\title{
Antibiotic susceptibility pattern and biofilm formation in coagulase negative staphylococci
}

\author{
Olayemi O Ayepola ${ }^{1}$, Nurudeen A Olasupo ${ }^{2}$, Louis O Egwari ${ }^{1}$, Frieder Schaumburg ${ }^{3}$ \\ ${ }^{1}$ Department of Biological Sciences, Covenant University Ota, Ogun State Nigeria \\ ${ }^{2}$ Department of Microbiology, Lagos State University, Ojo, Lagos, Nigeria \\ ${ }^{3}$ Institute for Medical Microbiology, University Hospital, Münster, Germany
}

Key words: Coagulase negative staphylococci; Antimicrobial susceptibility; Biofilm; VITEK-2 system.

J Infect Dev Ctries 2014; 8(12):1643-1645. doi:10.3855/jidc.5008

(Received 17 March 2014 - Accepted 25 August 2014)

Copyright (c) 2014 Ayepola et al. This is an open-access article distributed under the Creative Commons Attribution License, which permits unrestricted use, distribution, and reproduction in any medium, provided the original work is properly cited.

\section{Introduction}

Coagulase negative staphylococci (CoNS) are commensals of non-sterile sites in humans and become pathogenic mostly when the host is immunocompromised by prior diseases or invasive surgical or related procedures [1]. Slime or biofilm production by CoNS has been identified as an important factor in the pathogenesis of infections as bacteria organized in biofilms are protected from the action of antibiotics and the immune system [2]. Biofilm is ascribed the most important virulence factor of $S$. epidermidis as it enables attachment and persistence of the bacteria on foreign materials $[3,4]$. Other studies have indicated a correlation between antibiotic resistance and slime expression. For instance, insertion of a certain transposon influences both biofilm formation and the expression of methicillin resistance in S. epidermidis [4]. In another study methicillin resistance was found to be significantly higher in slime positive isolates $(81 \%)$ than in slime negative isolates (57\%) [5]. Due to the frequent recovery of CoNS in clinical infections their antibiotic susceptibility profile as well as their biofilm forming ability was investigated in this study.

\section{The Study}

One hundred clinical strains of CoNS comprising S. cohnii $(\mathrm{n}=7), S$. cohnii ssp. urealyticus $(\mathrm{n}=12), S$. epidermidis $(\mathrm{n}=5), S$. haemolyticus $(\mathrm{n}=20), S$. hominis $(\mathrm{n}=26), S$. intermedius $(\mathrm{n}=4), S$. klosii $(\mathrm{n}=$ 4), $S$. lugdunensis $(\mathrm{n}=4), S$. saprophyticus $(\mathrm{n}=7), S$. sciuri $(\mathrm{n}=5), S$. warneri $(\mathrm{n}=3)$ and $S$. xylosus $(\mathrm{n}=3)$ were isolated from various clinical specimens obtained from wards and outpatient departments of 8 medical centres from the states of Lagos and Ogun in Nigeria. The isolates were identified by cultural and biochemical characteristics. Identification to species level was performed with the VITEK-2 automated system (bioMérieux, Marcy l'Etoile, France). Susceptibility to 19 different antimicrobial agents (benzylpenicillin, oxacillin [methicillin], gentamicin, tobramycin, levofloxacin, moxifloxacin, erythromycin, clindamycin, linezolid, teicoplanin, vancomycin, tetracycline, tigecycline, fosfomycin, nitrofurantoin, fusidic acid, mupirocin, rifampicin and trimethoprimsulfamethoxazole) was tested with the VITEK-2 automated system. The biofilm- forming capacity of one S. lugdunensis strain and five $S$. epidermidis strains obtained in this study was investigated by a method previously described [6].

Antibiotic resistance by the CoNS was highest against tetracycline $(74.7 \%)$ followed by penicillin $(69.5 \%)$ and fosfomycin (68.4\%). Mupirocin and nitrofurantoin produced the highest in vitro activities against the CoNS. Staphylococcus intermedius and $S$. xylosus exhibited extreme resistance to most of the antibiotics tested. Resistance to methicillin was $41 \%$ (Table 1). The ratio of methicillin susceptible (MS) CoNS to methicillin resistant (MR) CoNS was approximately $2: 1$ (59\% to $41 \%)$. High level resistance to methicillin was evident in S. intermedius (100\%), $S$. xylosus $(100 \%) \quad S$. haemolyticus $(95 \%)$ and $S$. epidermidis (60\%). 
Table 1. Antimicrobial resistance profile of coagulase negative staphylococcal strains

\begin{tabular}{|c|c|c|c|c|c|c|c|c|c|c|c|c|}
\hline Antibiotics & S. cohnii & $\begin{array}{c}\text { S. cohnii } \\
\text { urealytic } \\
\text { us }\end{array}$ & $\begin{array}{c}S . \\
\text { epidermi } \\
\text { dis }\end{array}$ & $\begin{array}{c}S . \\
\text { haemoly } \\
\text { ticus }\end{array}$ & $\begin{array}{c}S . \\
\text { hominis }\end{array}$ & $\begin{array}{c}S . \\
\text { intermed } \\
\text { ius }\end{array}$ & $\begin{array}{c}S . \\
\text { kloosii }\end{array}$ & $\begin{array}{c}S . \\
\text { lugdune } \\
\text { nsis }\end{array}$ & $\begin{array}{c}S . \\
\text { sapropht } \\
\text { icus }\end{array}$ & S. sciuri & $\begin{array}{c}S . \\
\text { warneri }\end{array}$ & $\begin{array}{c}\text { S. } \\
\text { xylosus }\end{array}$ \\
\hline $\mathbf{P}$ & 42.9 & 75 & 100 & 100 & 23.1 & 100 & 75 & 0 & 100 & 100 & 100 & 100 \\
\hline OX & 28.6 & 25 & 60 & 95 & 11.5 & 100 & 0 & 0 & 42.8 & 0 & 33.3 & 100 \\
\hline GM & 0 & 0 & 40 & 30 & 7.7 & 100 & 0 & 0 & 0 & 20 & 0 & 33.3 \\
\hline TM & 0 & 0 & 40 & 25 & 7.7 & 100 & 0 & 0 & 0 & 20 & 0 & 100 \\
\hline LEV & 0 & 0 & 40 & 70 & 7.7 & 100 & 0 & 0 & 0 & 20 & 33.3 & 33.3 \\
\hline MXF & 0 & 0 & 0 & 25 & 0 & 100 & 0 & 0 & 0 & 20 & 33.3 & 100 \\
\hline $\mathbf{E}$ & 0 & 16.7 & 40 & 20 & 7.7 & 100 & 75 & 0 & 0 & 0 & 33.3 & 100 \\
\hline $\mathrm{CN}$ & 0 & 18.3 & 40 & 20 & 3.8 & 100 & 25 & 0 & 0 & 80 & 33.3 & 100 \\
\hline LNZ & 0 & 0 & 0 & 0 & 0 & 100 & 0 & 0 & 0 & 0 & 0 & 100 \\
\hline TEC & 0 & 0 & 0 & 0 & 0 & 100 & 0 & 0 & 0 & 0 & 0 & 100 \\
\hline VAN & 0 & 0 & 0 & 0 & 0 & 100 & 0 & 0 & 0 & 0 & 0 & 100 \\
\hline TE & 57.1 & 58.3 & 100 & 85 & 80.8 & 100 & 24 & 100 & 71.4 & 60 & 66.7 & 100 \\
\hline TGC & 0 & 0 & 0 & 0 & 0 & 100 & 0 & 0 & 0 & 0 & 0 & 0 \\
\hline FOS & 71.4 & 25 & 0 & 85 & 88.5 & 100 & 100 & 100 & 71.4 & 0 & 100 & 0 \\
\hline NIT & 0 & 0 & 0 & 0 & 0 & 50 & 0 & 0 & 0 & 0 & 0 & 0 \\
\hline FA & 100 & 91.7 & 0 & 10 & 11.5 & 100 & 75 & 0 & 100 & 100 & 33.3 & 100 \\
\hline MUP & 0 & 0 & 0 & 0 & 0 & 0 & 0 & 0 & 0 & 0 & 0 & 0 \\
\hline RIF & 0 & 0 & 0 & 10 & 3.8 & 100 & 0 & 0 & 14.2 & 0 & 0 & 100 \\
\hline SXT & 0 & 0 & 40 & 90 & 15.4 & 100 & 25 & 0 & 57.1 & 0 & 33.3 & 100 \\
\hline
\end{tabular}

*Values represent percentages

P: benzylpenicillin; OX: oxacillin; GM: gentamicin; TM: tobramycin; LEV: levofloxacin; MXF: moxifloxacin; E: erythromycin; CN: clindamycin; LNZ: linezolid; TEC: teicoplanin; VAN: vancomycin; TE: tetracycline; TGC: tigecycline; FOS: fosfomycin; NIT: nitrofurantoin; FA: fusidic acid; MUP: mupirocin; RIF: rifampcin; SXT: trimethoprim-sulfamethoxazole.

Figure 1. Antimicrobial resistance patterns of MRCoNS and MSCoNS

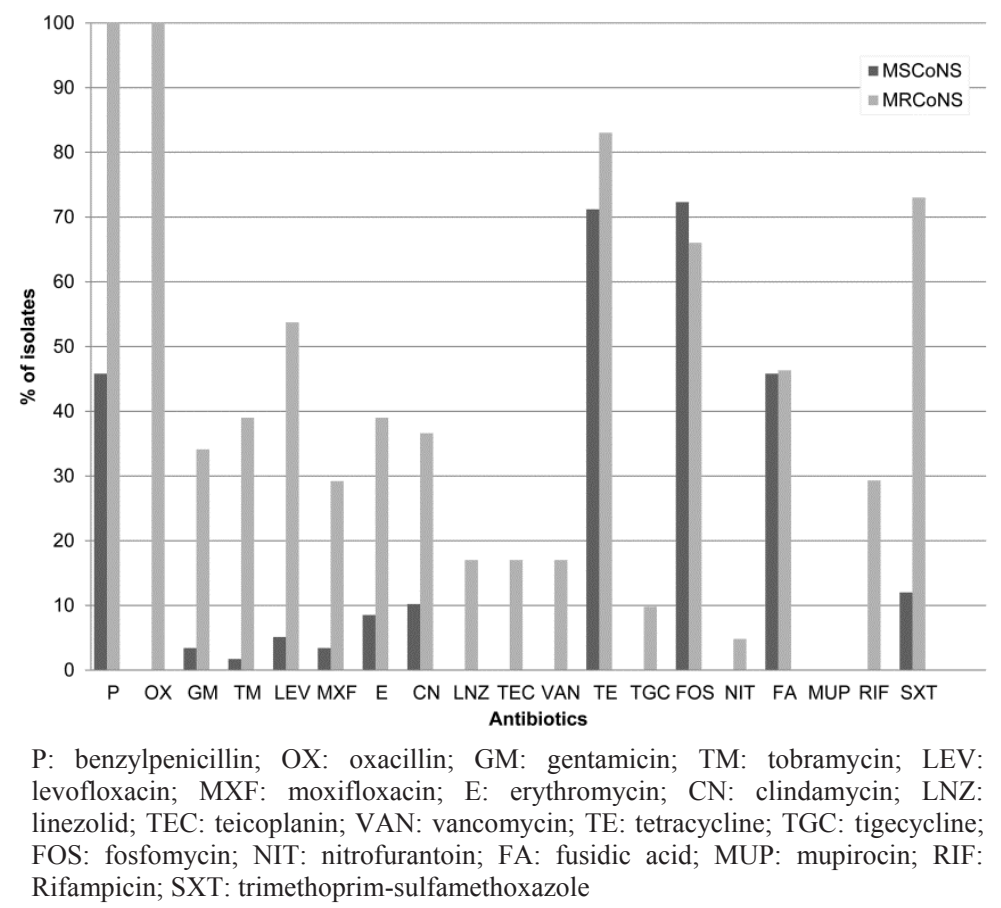


A comparison of the antibiotic susceptibilities of (MS) CoNS and (MR) CoNS showed that MR CoNS were more resistant (Figure 1). Biofilm formation was observed in three of the $S$. epidermidis strains tested. The S. lugdunensis strain did not form biofilm.

The results of the antibiotic susceptibility test showed that the $\beta$-lactam antibiotics were less effective, particularly the penicillins against CoNS. The emergence of large clusters of methicillin resistant CoNS in this study portend further therapeutic dilemma. These strains have been shown to spread within and between hospitals $[7,8]$. The $41 \%$ of CoNS which were methicillin resistant in this present study is encouragingly lower than the proportion (60-70\%) seen in some hospitals in Europe [9]. Mupirocin's excellent activity against the CoNS is important as it will continue to be the drug of choice for decontaminating the nasal cavity of carriers of staphylococci [10].

The resistance pattern in $S$. intermedius and $S$. xylosus as seen in this present study is of major concern. Of particular interest is the $100 \%$ resistance of these two species to antibiotics (methicillin, linezolid, teicoplanin, vancomycin, tigecycline with the exception of mupirocin) that produced 100\% activity against other species. The present study showed that organisms that lacked the ability to form biofilms were more susceptible to antibiotics. It is important to observe also that two of the five strains of $S$. epidermidis that failed to form biofilms represented the antibiotic sensitive clone. Our finding supports an earlier work that methicillin resistance in CoNS was higher in species that produce slime [5]. It is worthwhile to note that several of the isolates in this study could be contaminants and not real pathogens.

In conclusion, further studies are required to determine the epidemiological implication of diversified resistance in coagulase negative staphylococci.

\section{Acknowledgements}

The support to Ayepola O.O by the European Molecular Biology Organization and the Institute for Medical Microbiology, University Hospital, Münster, Germany is gratefully recognized by the authors.

\section{References}

1. Raad I, Alrahwan A, Rolston K (1998) Staphylococcus epidermidis: emerging resistance and need for alternative agents. Clin Infect Dis 26: 1182-1187.

2. Kloos WE, Bannerman TL (1994) Update on clinical significance of coagulase-negative Staphylococci. Clin Microbiol Rev 7: 117-140.

3. von Eiff C, Peters G, Heilmann C (2002) Pathogenesis of infections due to coagulase negative staphylococci. Lancet Infect Di 2: 677-685.

4. Mack D, Davies AP, Harris LG, Rohde H, Horstkotte MA, Knobloch JK (2007) Microbial interactions in Staphylococcus epidermidis biofilms. Anal Bioanal Chem 387: 399-408.

5. Koksal F, Yasar H, Samasti M (2007) Antibiotic resistance patterns of coagulase negative staphylococcus strains isolated from blood cultures of septicemic patients in Turkey. Microbiol Res 164: 404-410.

6. Heilmann C, Gerke C, Perdreau-remington F, Gotz F (1996) Characterization of $\operatorname{Tn} 917$ insertion mutants of Staphylococcus epidermidis affected in biofilm formation. Infect Immun 664: 277-282.

7. Widerström M, Monsen T, Karlsson C, Wiström J (2006) Molecular epidemiology of methicillin-resistant coagulasenegative staphylococci in a Swedish county hospital: evidence of intra and inter hospital clonal spread. J Hosp Infect 64: 177-183.

8. Monsen T, Olofsson C, Rönmark M, Wiström J (2000) Clonal spread of staphylococci among patients with peritonitis associated with continuous ambulatory peritoneal dialysis. Kidney Int 57: 613-618.

9. Stefani S, Varaldo PE (2003). Epidemiology of methicillinresistant staphylococci in Europe. Clin Microbiol Infect 9: 1179-86.

10. Perl TM, Cullen JJ, Wenzel RP, Zimmerman MB, Pfaller MA, Sheppard D, Twombley J, French PP, Herwaldt LA; Mupirocin and The Risk Of Staphylococcus aureus Study Team (2002) Intranasal mupirocin to prevent postoperative Staphylococcus aureus infections. N Engl J Med 346: 1871-7.

\author{
Corresponding author \\ Olayemi.O. Ayepola \\ Department of Biological Sciences, College of Science and \\ Technology \\ Covenant University, P.M.B. 1023 \\ Ota, Ogun State, Nigeria. \\ Phone: +2348034785269 \\ Email: ola.ayepola@covenantuniversity.edu.ng
}

Conflict of interests: No conflict of interests is declared. 